\title{
Lyme Borreliosis in Human Patients in Florida and Georgia, USA
}

\author{
Kerry L. Clark ${ }^{1,}$, Brian Leydet $^{1,2}$, and Shirley Hartman ${ }^{3}$ \\ 1. Department of Public Health, University of North Florida, 1 UNF Drive, Jacksonville, Florida USA 32224; \\ 2. Current address: Department of Pathobiological Sciences, Louisiana State University, Baton Rouge, Louisiana USA 70803; \\ 3. Mandarin Wellness Center, Jacksonville, Florida, USA 32257.
}

$\triangle$ Corresponding author: Kerry L. Clark, M.P.H., Ph.D., Department of Public Health, University of North Florida, 1 UNF Drive, Jacksonville, FL 32224. Phone: (904) 620-1427. Fax: (904) 620-2848. E-mail: kclark@unf.edu.

() Ivyspring International Publisher. This is an open-access article distributed under the terms of the Creative Commons License (http://creativecommons.org/ licenses/by-nc-nd/3.0/). Reproduction is permitted for personal, noncommercial use, provided that the article is in whole, unmodified, and properly cited.

Received: 2013.03.18; Accepted: 2013.04.15; Published: 2013.05 .23

\begin{abstract}
The aim of this study was to determine the cause of illness in several human patients residing in Florida and Georgia, USA, with suspected Lyme disease based upon EM-like skin lesions and/or symptoms consistent with early localized or late disseminated Lyme borreliosis. Using polymerase chain reaction (PCR) assays developed specifically for Lyme group Borrelia spp., followed by DNA sequencing for confirmation, we identified Borrelia burgdorferi sensu lato DNA in samples of blood and skin and also in lone star ticks (Amblyomma americanum) removed from several patients who either live in or were exposed to ticks in Florida or Georgia. This is the first report to present combined PCR and DNA sequence evidence of infection with Lyme Borrelia spp. in human patients in the southern U.S., and to demonstrate that several B. burgdorferi sensu lato species may be associated with Lyme disease-like signs and symptoms in southern states. Based on the findings of this study, we suggest that human Lyme borreliosis occurs in Florida and Georgia, and that some cases of Lyme-like illness referred to as southern tick associated rash illness (STARI) in the southern U.S. may be attributable to previously undetected B. burgdorferi sensu lato infections.
\end{abstract}

Key words: Lyme borreliosis, Florida, Georgia

\section{Introduction}

Lyme borreliosis (LB), the most frequently reported arthropod-borne infection in the United States [1], is caused by several species within the Borrelia burgdorferi sensu lato genogroup. Borrelia burgdorferi sensu lato includes at least 20 genospecies worldwide, seven of which are present in North America: $B$. americana, $B$. andersonii, $B$. bissettii, $B$. burgdorferi sensu stricto (hereafter referred to as just B. burgdorferi), $B$. californiensis, B. carolinensis, and B. kurtenbachii [2-9]. Borrelia burgdorferi has been widely reported as the only genospecies responsible for human disease in the U.S.; however, strains similar to B. bissettii have been identified in serum of several human cases in California using molecular methods [10].
In the northeastern U.S., B. burgdorferi spirochetes are transmitted to humans most commonly by nymphal stages of the blacklegged tick, Ixodes scapularis [11], and maintained in nature primarily by small rodents [7, 12-13]. In the southern and western U.S., immature stages of the Ixodes spp. vector ticks for $B$. burgdorferi feed primarily on lizards $[14,15,16]$. Borrelia burgdorferi sensu lato spirochetes have been isolated from birds, rodents, and ticks in southern and western states [6, 7, 17-19], and have been detected by molecular methods in wild lizards in Florida, South Carolina, and Maryland [20, 21]. Despite hundreds of reported cases of human Lyme disease from southern states each year, however, B. burgdorferi sensu lato 
have been isolated in culture from only a few human cases in the region [22-23].

Since the first report describing molecular detection of the hard tick relapsing fever group Borrelia species B. lonestari [24], numerous studies have been published describing its presence throughout the eastern U.S. where it has been shown to commonly infect lone star ticks (Amblyomma americanum) [25-31]. This organism has been considered and investigated as the possible cause of Lyme-like illness, often referred to as southern tick associated rash illness (STARI), in humans in the southern U.S. [25, 27, 29, 31-33]. However, despite the efforts to date, very little evidence has been obtained that supports the notion that $B$. lonestari is the cause of STARI [34]. For example, a microbiologic study of 30 Missouri patients with erythema migrans (EM)-like skin lesions concluded that neither B. burgdorferi nor B. lonestari was likely to be the cause [33], because the investigators were unable to culture spirochetes from skin biopsy specimens from any of the patients. A study of 14 cases of EM-like rash illness at a camp in North Carolina also failed to isolate spirochetes from patient skin biopsies. Only two patients had positive B. burgdorferi ELISA results using flagellar antigens, but nine of 14 had IgM and IgG Western immunoblot 41-kDa (flagellin) positive bands on acute and earliest convalescent phase samples [35], which is suggestive of possible Borrelia sp. infection [36]. Another similar study of 17 patients with EM lesions in Missouri [37] also failed to isolate spirochetes in BSK medium; however several patients had positive Western Blot bands, including that for the 41-kDa protein and others that are suggestive of a Borrelia sp. infection [37], but also not providing evidence conclusive of Lyme borreliosis. All of these findings have led investigators to pursue the hypothesis that some Borrelia sp. other than B. burgdorferi sensu lato was responsible for the observed human Lyme-like manifestations. Nevertheless, to date only one published case report has documented evidence of the presence of B. lonestari in association with early Lyme-like illness and an EM-like skin lesion in a patient with an attached lone star tick obtained in either North Carolina or Maryland [32].

Complicating the investigation of the cause of Lyme-like illness in the southern U.S. is the presence of other tickborne pathogens that are known to occur in the region. These include, for example, Anaplasma phagocytophilum [38-39], the cause of human granulocytic anaplasmosis, Ehrlichia chaffeensis [40], the cause of human monocytic ehrlichiosis, Babesia microti [41], the primary cause of human babesiosis in the U.S. [42], and Rickettsia spp. [43].

The aim of this study was to determine the cause of illness in several human patients residing in Florida and Georgia, USA, with suspected Lyme disease based upon EM-like skin lesions and/or symptoms consistent with early localized or late disseminated Lyme borreliosis. Using polymerase chain reaction assays (PCR) specific for Lyme group Borrelia spp., followed by DNA sequencing for confirmation, we identified B. burgdorferi sensu lato DNA in samples of blood and skin, and also in lone star ticks removed from several patients who either live in or were exposed to ticks in Florida or Georgia. This is the first report to show combined PCR and DNA sequence evidence of infection with Lyme Borrelia spp. in human patients in the southern U.S., and to demonstrate that several B. burgdorferi sensu lato species may be associated with Lyme disease-like signs and symptoms in southern states.

\section{Materials and Methods}

Human patient and control samples. Beginning in 2003, the University of North Florida Environmental Epidemiology Laboratory (UNF Lab) began receiving for microbiologic testing human blood or other body fluids, skin biopsy samples, and attached ticks from patients suspected of having Lyme disease (UNF IRB approval \#06-140) as part of ongoing studies of tick-borne diseases in the southern U.S. The present study describes results for samples submitted by attending physicians of 10 patients during the period March 2003 through December 2012. As part of the study, a questionnaire was completed for each patient to obtain basic demographic data, travel history prior to onset of signs/symptoms, tick exposure, and clinical data. Details of samples obtained and tested for each patient are described below in the results section. As part of the study, in 2007 we also obtained blood from 12 control patient samples provided by an internal medicine practice in central Florida. The control patients did not have symptoms consistent with borreliosis. These samples were used for multiple negative control DNA extractions utilized in PCR testing throughout the remainder of the study.

Borrelia culture isolation. Spirochete culture isolation was attempted with multiple samples of whole blood or plasma (aliquots of 100 to $500 \mu \mathrm{l}$ per culture) preserved in EDTA from a few patients, and from 2-mm skin biopsy punch specimens taken from EM lesions from two patients. Each template type was inoculated into tubes containing $4 \mathrm{~mL}$ of BSK-H complete culture medium supplemented with antibiotics (Sigma, St. Louis, MO) for isolating Borrelia [44], incubated at $33^{\circ} \mathrm{C}$, and examined weekly for spirochetes by darkfield microscopy for a minimum of eight 
weeks. During each attempt to culture spirochetes from a human patient, samples from a B. burgdorferi strain B31 reference strain were also inoculated and maintained in culture to ensure the ability of the medium to support spirochete growth.

DNA extraction. For all samples, DNA extractions were done inside a Class II biosafety cabinet, and utilized a commercially available kit (MasterPure, Epicentre, Madison, WI) with optimized modifications of the manufacturer's protocols as described below. DNA was extracted from 2-mm skin punch biopsies, dried blood spots (obtained from one patient), and ticks in the same manner as that used for dried blood spots or tick specimens in previous studies [20, 45]. From 300 to $500 \mu \mathrm{l}$ of EDTA anticoagulated blood, or $100 \mu \mathrm{l}$ of plasma, was used as starting template for DNA extractions from patient and control EDTA whole blood samples by adjusting the proportion of kit reagents according to the manufacture's recommendations. DNA pellets were rehydrated with $100 \mu \mathrm{l}$ of TE buffer. Negative control samples free of any template were included in each round of DNA extractions.

PCR testing. Extracts from all samples were screened by nested PCR using primer sets designed to amplify a portion of the conserved $41-\mathrm{kDa}$ chromosomal flagellin gene $($ flaB) from $B$. burgdorferi sensu lato. Some samples received earlier in the study were tested with a previously described flaB gene PCR [20, 45]. Additionally, all samples obtained after 2006 were screened with newer primers: outer reaction primers 280F (5'-GCA-GTT-CAR-TCA-GGT-AAC-GG-3', bp 280-299) and 754R (5'-TAG-CAA-GTG-ATG-TATTRG-CAT-CAA-C-3', bp 754-730), which amplify a 475-bp product; and inner reaction primers $301 \mathrm{~F}$ (5'ACA-TAT-TCA-GAT-GCA-GAC-AGA-GG-3', bp 301-323) and 737R (5'-GCA-TCA-ACT-GTR-GTTGTA-ACA-TTA-ACA-GG-3', bp 737-709) that amplify a 437-bp product or 301F plus 690R (5'-GAA-GGTGCT-GTA-GCA-GGT-GCT-GGC-3') [46] that amplifies a 390-bp product.

First round PCR amplifications contained $2.5 \mu \mathrm{l}$ of DNA extract per individual sample in a total reaction volume of $25 \mu \mathrm{l}$. Each inner/nested reaction used $1 \mu \mathrm{l}$ of outer reaction product as template. All reactions utilized GoTaqGreen ${ }^{\circledR}$ PCR master mix (Promega, Madison, WI) resulting in a final concentration of $1.25 \mathrm{U}$ of Taq DNA polymerase, $1.5 \mathrm{mM}$ $\mathrm{MgCl}_{2}, 200 \mu \mathrm{M}$ of each deoxynucleoside triphosphate, and $0.8 \mu \mathrm{M}$ of each primer, and were carried out in an automated DNA thermal cycler (PTC 200, MJ Research, Watertown, MA). Each primary PCR consisted of initial denaturation at $94^{\circ} \mathrm{C}$ for $2.5 \mathrm{~min}$, followed by 35 cycles of $94^{\circ} \mathrm{C}$ for $30 \mathrm{sec}$, primer annealing at $52^{\circ} \mathrm{C}$,
$30 \mathrm{~s}$, and extension at $72^{\circ} \mathrm{C}$ for $45 \mathrm{sec}$, with a final extension at $72^{\circ} \mathrm{C}$ for $5 \mathrm{~min}$. Nested reactions included initial denaturation at $94^{\circ} \mathrm{C}$ for $1.5 \mathrm{~min}$, followed by 35 cycles as described for outer reactions, but with an annealing temperature of $55^{\circ} \mathrm{C}$.

PCRs were set up in an area separate from DNA extractions, and within a PCR clean cabinet (CleanSpot Workstation, Coy Laboratory Products, Grass Lake, MI) equipped with a germicidal UV lamp. Other precautions to prevent carryover contamination of amplified DNA included different sets of pipettes dedicated for DNA extraction, PCR setup, and post-amplification activities, the use of aerosol barrier filter pipet tips, and soaking pipettes used for handling DNA samples in $10 \%$ bleach solution after setup of each PCR. Each outer PCR included a negative control sample with nuclease free TE buffer as template, and a positive control sample from B. burgdorferi B31 culture extract. Negative control patient blood samples were included routinely in DNA extractions and PCR testing throughout the study period. A portion of the positive and negative control outer reaction PCR samples was carried over as template in each nested reaction, just as for study patient samples. PCR products were electrophoresed in $2 \%$ agarose gels, which were stained with ethidium bromide, and visualized and recorded with a digital gel documentation unit.

DNA sequence analysis. PCR products from positive samples were purified using the Wizard ${ }^{\circledR} \mathrm{SV}$ Gel and PCR Clean-Up System (Promega, Madison, WI). DNA templates were sequenced [45] using both the forward and reverse primers used in the nested PCRs. Investigator-derived sequences were compared with those obtained by searching the GenBank database (National Center for Biotechnology Information) using the Basic Local Alignment Search Tool (BLAST) [48], and aligned using Clustal X [49]. Unique nucleotide differences among sequences in this study compared to reference strains were confirmed by comparing both the forward and reverse primer sequence data. A phylogenetic tree was constructed using the Neighbor Joining (NJ) method [50, 51] with the tree-building program MEGA5 [52]. To estimate node reliability, bootstrap values [53] based on an analysis of 1,000 replicates were determined. Evolutionary distances were computed by the maximum composite likelihood method [54].

Nucleotide sequence accession numbers. The GenBank accession numbers for B. burgdorferi sensu lato $\mathrm{flaB}$ gene sequences generated in the present study are FJ188419, FJ188427, FJ188428, FJ188430, and KC607890 through KC607901. Borrelia burgdorferi sensu lato reference strain flaB sequences in Genbank 
included in comparisons are: B. burgdorferi B31 (X15661), JD-1 (CP002312), and SCI-2 (AF264885); B. americana SCW-30h (AF264886) and SCW-33 (EU081293); B. andersonii 19857 (D83762) and SI-10 (AF264883); B. bissettii DN127 (D82857); B. carolinensis SCGT-18 (EU076498); B. kurtenbachii 25015 (FJ188426); B. afzelii ACA1 (X75202); and B. garinii Ip90 (X75203).

\section{Results}

Using the same methods as those described for experimental patients, blood samples from control patients all tested negative by PCR for Lyme Borrelia DNA. Table 1 describes demographic and clinical characteristics and tick bite history for the patients, along with PCR testing results for ticks removed from a few patients. Table 2 summarizes the patients' clinical laboratory test results for Lyme disease, the present study's PCR testing and DNA sequence results for $B$. burgdorferi sensu lato, and patient diagnoses from different health care providers.
Patient 1. In April 2003, the UNF Lab received a blood sample submitted by a clinician in St. Mary's, Georgia for a patient who sought care for a suspicious skin rash and vague flu-like symptoms following a tick bite (sp. not identified) acquired in March. The patient was a 23-year-old female college student who had not traveled outside the Jacksonville, FL and St. Mary's, GA area for several years. The patient had a disseminated rash consisting of faint multiple round and oval lesions (no less than 20 documented and measured) between 1 and $5 \mathrm{~cm}$ diameter, some with and some without clear central areas, located on her arms, legs, hips, and back. The patient reported that the rash had been present for about one month. The attending clinician also sent a blood sample to a clinical diagnostic laboratory for Lyme enzyme immunoassay (EIA) antibody testing. The patient was diagnosed with a viral infection, but a two-week course of oral doxycycline was prescribed. The rash resolved over the next several weeks.

Table I. Demographic and clinical characteristics of study patients, and Borrelia burgdorferi sensu lato detected in attached ticks.

\begin{tabular}{|c|c|c|c|c|c|c|c|c|c|}
\hline Patient & Age (yr) & Gender & $\begin{array}{l}\text { Residence } \\
\text { (state) }\end{array}$ & Primary symptoms & $\begin{array}{l}\text { Duration } \\
\text { of illness }\end{array}$ & Persistent symptoms & EM lesion & Tick bite history & $\begin{array}{l}\text { Tick PCR } \\
\text { result }\end{array}$ \\
\hline 1 & 23 & $\mathrm{~F}$ & GA & Fatigue & $8 \mathrm{yr}$ & $\begin{array}{l}\text { Fatigue, rashes, iritis, } \\
\text { arthralgia, colitis }\end{array}$ & $\begin{array}{l}\text { Multiple, dis- } \\
\text { seminated, } \\
\text { recurrent }\end{array}$ & $\begin{array}{l}\text { Single (un- } \\
\text { known sp.) }\end{array}$ & - \\
\hline 2 & 50 & $\mathrm{~F}$ & FL & $\begin{array}{l}\text { Headache, fatigue, } \\
\text { fitful sleep, cogni- } \\
\text { tive }\end{array}$ & $27 \mathrm{yr}$ & $\begin{array}{l}\text { Fatigue, cognitive, } \\
\text { arthralgia, fever, chills, } \\
\text { rashes }\end{array}$ & Multiple & $\begin{array}{l}\text { Multiple (un- } \\
\text { known spp.) }\end{array}$ & - \\
\hline 3 & 25 & $\mathrm{~F}$ & FL & $\begin{array}{l}\text { Fatigue, } \\
\text { headache }\end{array}$ & $2 \mathrm{mo}$ & None & Single & $\begin{array}{l}\text { Suspected adult } \\
\text { I. scapularis }\end{array}$ & - \\
\hline 4 & 4 & $\mathrm{~F}$ & GA & $\begin{array}{l}\text { Fatigue, } \\
\text { headache, } \\
\text { leg pain }\end{array}$ & $3 \mathrm{mo}$ & Not known & No & $\begin{array}{l}\text { A. americanum, } \\
\text { adult female }\end{array}$ & $\begin{array}{l}\text { B. burgdor- } \\
\text { feri }\end{array}$ \\
\hline 5 & 44 & $\mathrm{~F}$ & GA & $\begin{array}{l}\text { Nausea, arthralgia, } \\
\text { lymphadenopathy }\end{array}$ & $3 \mathrm{yr}$ & $\begin{array}{l}\text { Fatigue, arthralgia, } \\
\text { myalgia, cognitive }\end{array}$ & Single & $\begin{array}{l}\text { Multiple A. } \\
\text { americanum }\end{array}$ & - \\
\hline 6 & 38 & $\mathrm{~F}$ & FL & $\begin{array}{l}\text { Optic neuritis, fa- } \\
\text { tigue, headache, } \\
\text { neck/ back pain }\end{array}$ & $12 \mathrm{yr}$ & $\begin{array}{l}\text { Fatigue, headache, } \\
\text { neck/back pain, GI }\end{array}$ & Single & $\begin{array}{l}\text { Multiple (un- } \\
\text { known spp.) }\end{array}$ & - \\
\hline 7 & 50 & $\mathrm{M}$ & FL & None & $2 \mathrm{mo}$ & None & Single & $\begin{array}{l}\text { A. americanum, } \\
\text { adult female }\end{array}$ & $\begin{array}{l}\text { B. burgdor- } \\
\text { feri }\end{array}$ \\
\hline 8 & 49 & M & GA & $\begin{array}{l}\text { Tremors, balance, } \\
\text { foot drop }\end{array}$ & $7 \mathrm{yr}$ & $\begin{array}{l}\text { Motor function, bal- } \\
\text { ance }\end{array}$ & No & $\begin{array}{l}\text { Multiple ( } A \text {. } \\
\text { americanum sus- } \\
\text { pected) }\end{array}$ & - \\
\hline 9 & 42 & $\mathrm{M}$ & FL & $\begin{array}{l}\text { Lymphadenopathy, } \\
\text { fatigue, headache, } \\
\text { stiff neck }\end{array}$ & $2 \mathrm{yr}$ & $\begin{array}{l}\text { Fatigue, headache, stiff } \\
\text { neck }\end{array}$ & No & $\begin{array}{l}\text { A. americanum, } \\
\text { nymphs and } \\
\text { adults }\end{array}$ & - \\
\hline 10 & 69 & M & FL & $\begin{array}{l}\text { Arthralgia, cogni- } \\
\text { tive, prostatitis }\end{array}$ & $1 \mathrm{yr}$ & Cognitive, prostatitis & No & Uncertain & - \\
\hline
\end{tabular}


Table 2. Results for Lyme enzyme immunoassay (EIA) and Western Blot (WB) antibody tests, BSK spirochete culture, and Borrelia burgdorferi sensu lato PCR test results, and clinical diagnoses of study patients.

\begin{tabular}{|c|c|c|c|c|c|c|}
\hline Patient & Samplea & Lyme EIA & Lyme WB & BSK culture & B. burgdorferi $\mathrm{PCR}^{\mathrm{b}}$ & Diagnoses ${ }^{c}$ \\
\hline \multirow[t]{2}{*}{1} & Serum (Apr 2003) & $\mathrm{Neg}$ & - & - & - & Chronic viral \\
\hline & Blood (Apr 2003) & - & - & - & B. andersonii & infection, colitis \\
\hline \multirow[t]{4}{*}{2} & Serum (1994) & - & - & - & - & $\begin{array}{l}\text { Fibromyalgia, CFS, } \\
\text { Meniere's }\end{array}$ \\
\hline & Urine (1998) & - & - & - & - & disease, RA, lupus, MS, \\
\hline & Blood (Feb 2004) & - & - & Neg & B. americana & Lyme disease, \\
\hline & Blood (Feb 2009) & - & - & - & B. americana & babesiosis \\
\hline \multirow[t]{3}{*}{3} & Serum (Nov 2007) & Neg & - & - & - & Lyme disease \\
\hline & Blood (Nov 2007) & - & - & Neg & B. americana & \\
\hline & Skin biopsy (Nov 2007) & - & - & Neg & B. americana & \\
\hline \multirow[t]{2}{*}{4} & Serum (Apr 2009) & Neg & - & - & - & Not known \\
\hline & Blood (Apr 2009) & - & - & - & B. burgdorferi & \\
\hline \multirow[t]{3}{*}{5} & Serum (Apr 2009) & Equivocal & - & - & - & Sinus infection, \\
\hline & Serum/Blood (Jun 2010) & Neg & - & - & B. burgdorferi & sleep apnea \\
\hline & Serum, Blood (Jul 2010) & - & $\operatorname{IgM} 18,23-25,34,41,58$ & - & Neg & \\
\hline \multirow[t]{5}{*}{6} & Serum (May 2001) & Pos (1.31) & $\operatorname{IgG} 41$ & - & - & Optic neuritis, \\
\hline & Serum (Nov 2001) & $\operatorname{Pos}(1.52)$ & IgM 23; IgG 41 & - & - & MS, Lyme \\
\hline & Blood (Jan 2010) & - & - & - & B. andersonii & disease \\
\hline & Blood (Feb 2010) & - & - & - & B. burgdorferi & \\
\hline & Plasma (Dec 2012) & - & - & - & B. burgdorferi & \\
\hline \multirow[t]{4}{*}{7} & Serum (Apr 2010) & - & IgM 41; IgG 41 & Neg & - & Lyme disease \\
\hline & Blood (Apr 2010) & - & - & Neg & Neg & \\
\hline & Skin biopsy (Apr 2010) & - & - & Neg & B. burgdorferi & \\
\hline & Serum (Aug 2010) & - & IgM 41; IgG 41 & Neg & - & \\
\hline \multirow[t]{4}{*}{8} & Serum (Jul 2010) & - & $\operatorname{IgG} 41$ & - & - & ALS, Lyme \\
\hline & Serum (Jul 2011) & - & No bands & - & - & disease, \\
\hline & Blood (Dec 2011) & - & - & - & B. burgdorferi & babesiosis \\
\hline & Blood (Jun 2012) & - & - & - & B. burgdorferi & \\
\hline \multirow[t]{9}{*}{9} & Blood (Jun 2010) & - & - & - & Neg & Lyme disease \\
\hline & DBS (Dec 2010) & - & - & - & B. andersonii & \\
\hline & Serum (Jan 2011) & - & $\operatorname{IgM} 41$ & - & - & \\
\hline & Serum (Mar 2011) & - & No bands & - & - & \\
\hline & Blood/DBS (Dec 2011) & - & - & - & B. burgdorferi & \\
\hline & Serum (Jan 2012) & - & IgM 41; IgG 41, 39, 58 & - & - & \\
\hline & Serum/Blood (May 2012) & - & No Bands & - & Neg & \\
\hline & DBS (Jun 2012) & - & - & - & B. burgdorferi & \\
\hline & Blood/plasma (Dec 2012) & - & - & - & B. burgdorferi & \\
\hline \multirow[t]{2}{*}{10} & Serum (Dec 2012) & IFA $1: 40$ & $\begin{array}{l}\operatorname{IgM} 31,41,58 ; \operatorname{IgG} 18 \\
30,34,41,58\end{array}$ & - & - & CJD, Lyme disease \\
\hline & Plasma (Dec 2012) & - & - & - & B. burgdorferi & \\
\hline
\end{tabular}

aDBS = dried blood spot. ${ }^{b P C R}$ testing conducted at UNF Lab unless otherwise indicated. ${ }^{\mathrm{c}} \mathrm{ALS}=$ amyotrophic lateral sclerosis; $\mathrm{CFS}=$ chronic fatigue syndrome; $\mathrm{CJD}=$ Creutzfeldt-Jakob disease; $\mathrm{MS}=$ =multiple sclerosis; $\mathrm{RA}=$ rheumatoid arthritis.

The patient's Lyme EIA test result was negative, and further clinical laboratory testing for Lyme disease or other tickborne infections was not conducted. However, the UNF Lab extracted DNA from an aliquot of the same blood sample and tested it with a previously described B. burgdorferi sensu lato specific
flaB nested PCR assay [45]. Positive results were obtained with the primer set using $301 \mathrm{~F}$ and $690 \mathrm{R}$ as inner primers (the 737R primer was not in use in our lab at that time). The 355-bp flaB sequence (GenBank FJ188427) obtained from the patient's blood was identical to several sequences in Genbank for B. an- 
dersonii (e.g., strain SI-10, AF264883). Over the next few years, the patient experienced recurrent similar rashes, ocular manifestations such as iritis or conjunctivitis, constant fatigue, and arthralgias. Her symptoms persist to the present. All of these signs and symptoms were reported to have begun only after the tick bite and initial skin lesions in spring 2003, and she reports that no one else in her immediate or extended family experiences such symptoms.

Patient 2. Patient 2 was a 50 year old female who was bitten by a tick in Minnesota in 1984, and experienced a multi-lesion rash on her back that resolved without treatment. Two years later, she began experiencing headaches, fatigue, sleep disturbance, and cognitive problems. The patient moved to Jacksonville, FL in 1988, where she experienced another tick bite in 1990. Soon afterwards she developed vertigo, and was diagnosed with fibromyalgia and chronic fatigue syndrome at a clinic in Jacksonville. In 1992, various specialists in Gainesville, Miami, and Jacksonville evaluated her, and she was diagnosed by different doctors with Meniere's disease, rheumatoid arthritis, lupus, multiple sclerosis, and asthma.

In 1994, she tested borderline positive for Babesia microti antibody with a titer of 1:64. A different physician in Jacksonville, FL treated her for presumed borreliosis with intravenous ceftriaxone for three weeks, followed by oral doxycycline and azithromycin. Her symptoms improved for a while, but then returned. She remained ill, and in February 2004, suspecting persistent borreliosis, her physician submitted a whole blood sample to the UNF Lab for research testing. Blood samples were cultured in BSK as described above and DNA extracted from whole blood was tested for B. burgdorferi sensu lato flaB with primers being used in our lab at that time [20,43]. Results of culture and PCR testing were negative. However, a portion of the 2004 blood sample was stored frozen, and a new extraction from that sample tested in 2008 using the newer B. burgdorferi sensu lato specific primers (described in this paper) gave positive results. The resulting 427-bp sequence (GenBank FJ188428) was $99.8 \%$ identical $(426 / 427 \mathrm{bp})$ to $B$. burgdorferi sensu lato strain SCW-30h (GenBank AF264886), which was later characterized as the genospecies B. americana [9]. The patient's flaB sequence had a minimum of eight bp differences with B31 (GenBank X15661) and other B. burgdorferi strains (e.g, strain JD1, GenBank CP002312), which represent the next most similar genospecies sequences.

The patient moved to Georgia in 2004, and continued to experience extreme fatigue, low grade fevers, sleep problems, myalgia, arthralgia, recurrent rashes, pain in the bottom of her feet, shortness of breath, and cognitive problems. In February 2009, the patient's physician in GA submitted a new blood sample to the UNF Lab for testing. Culture was not attempted, but PCR results were positive for $B$. burgdorferi sensu lato flaB, and the sequence obtained was identical to the previously obtained B. americana flaB sequence. In 2009, the patient moved to North Carolina, where a physician diagnosed her with Lyme disease, babesiosis, and bartonellosis. She was recently being treated with doxycycline, cefdinir, and rifampin, with improvement of symptoms.

Patient 3. In November 2007, another female college student in her early twenties who lived in northern Florida was enrolled in the study after she saw a local clinician and received a presumptive diagnosis of Lyme disease. The patient sought care after experiencing flu-like symptoms and noticing an EM-like lesion on the back of her upper left arm (Fig. $1)$. One week prior to onset, she had visited a Florida panhandle state park. She reported that she and others in her party found several ticks on their clothing that day, but she did not notice any attached ticks. Approximately one week after beginning oral doxycycline treatment, both a blood sample and a tissue biopsy from the perimeter of the skin lesion were submitted to the UNF Lab by her clinician. After some non-specific flu-like symptoms lingered after the initial 21 days of treatment, another 30 days of doxycycline was prescribed, and the skin lesion and symptoms resolved without further recurrence. Culture isolation attempts with a portion of the skin biopsy and blood samples were negative for spirochetes. DNA samples extracted from the patient's blood and skin biopsy were tested with the different primer sets described above. Both sample types tested positive. The 427-bp sequences (GenBank FJ188430) differed by only one bp from the flaB sequence of $B$. americana strain SCW-30h. Two of the authors (KLC, BL) visited the same park in early December 2007 and collected several adult I. scapularis from their clothing. One male tick, designated Is-TSP1, tested positive for $B$. burgdorferi sensu lato $f l a B$, and the sequence (GenBank FJ188419) obtained was identical to that from the B. americana positive patient's sample.

Patient 4. In April 2009, the pediatrician for a four year-old female patient from the Atlanta, Georgia area submitted to the UNF Lab blood samples and a partially engorged tick that had been removed from the patient's scalp by her parents approximately one week prior to the onset of headache, fever, malaise, and leg pain. The tick was easily identified as an adult female Amblyomma americanum. No skin lesion was observed at the tick bite site. The patient's serum tested negative for Lyme antibodies by EIA at a clini- 
cal laboratory. DNA extracted from the patient's blood and the tick tested positive for B. burgdorferi sensu lato flaB DNA. The sequences derived from the patient's blood and the tick (GenBank KC607890 and KC607891, respectively) differed from each other by 1-bp. The 428-bp sequence obtained from the tick was identical to that for B. burgdorferi B31. The 430-bp sequence from the patient's blood was $99.8 \%$ (429/430-bp) identical to B31. The patient was treated with amoxicillin for one month with improvement of symptoms. Sometime within the next year, the patient's family moved, and contact was lost. Therefore, further follow up was not possible.

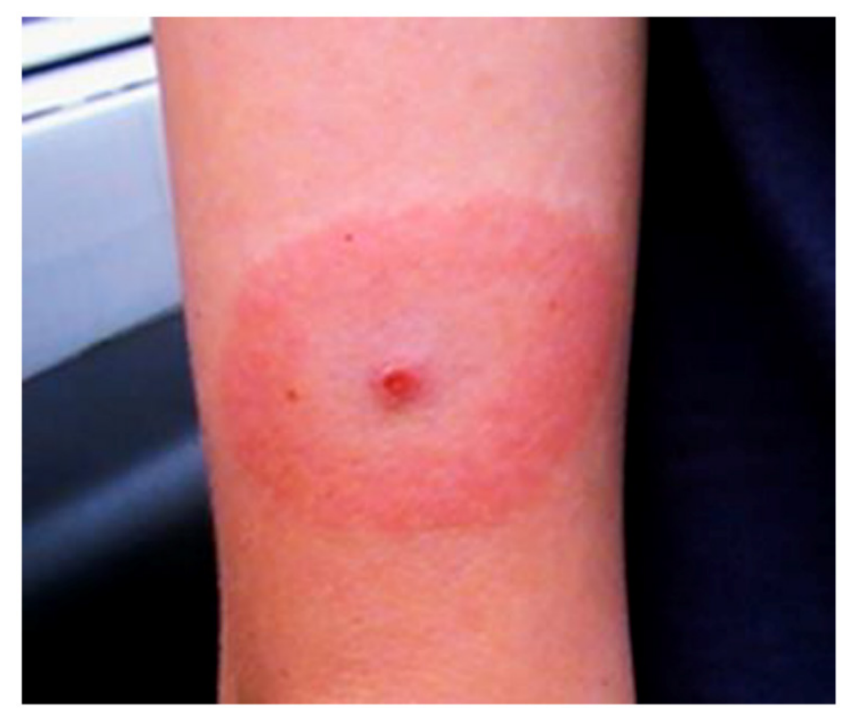

Fig I. Erythema migrans (EM)-like lesion on Patient 3 following tick exposure in northwestern Florida in November 2007. The lesion was located on the back of the left arm above the elbow. Note the suspected tick bite punctum in the center of the lesion.

Patient 5. Patient 5 was a 44 -year-old female living in Fayette County, GA with no travel outside the state, except for a vacation in the Caribbean months prior to the events described below. In April 2009 , she was bitten by a tick and subsequently developed an EM-like rash at the bite site. She also experienced nausea, joint pain, and lymphadenopathy. She was treated for two weeks with erythromycin. Shortly thereafter she received an equivocal $B$. burgdorferi EIA test result, but no follow up Lyme western blot was done. In May 2009 she was bitten by another tick, which she saved, and developed another rash similar to the previous one.

After experiencing continued fatigue, joint and neck pain, dizziness, and insomnia, she saw another physician in June. A blood sample and the previously collected tick were submitted to the UNF Lab for PCR testing. The female A. americanum tick tested negative for B. burgdorferi sensu lato flaB DNA. However, DNA extracted from the patient's whole blood was positive. The 437-bp sequence (GenBank KC607892) was identical to that for B. burgdorferi B31.

In May 2010, she was bitten by another tick identified as a female lone star tick at her doctor's office. She experienced headache, stiff neck, chills, fever, night sweats, swollen knee, brain fog, extreme fatigue, light and sound sensitivity, heart palpitations, shortness of breath, and tingling sensations in her legs and feet. In June 2010, the patient received negative results for the following tests (all at LabCorp): Lyme IgG/IgM EIA (Western Blot Reflex), Quantitative Lyme disease IgM EIA, Ehrlichia chaffeensis IgM and IgG titer, Anaplasma phagocytophilum (HGE) IgM and IgG titer, Rocky Mountain spotted fever (Rickettsia spp.) IgM and IgG EIA, and Lyme (B. burgdorferi) PCR. In July 2010, the patient's whole blood and serum tested negative for genomic and plasmid $B$. burgdorferi DNA (multiplex PCR) at IgeneX (Palo Alto, CA). Concurrently, she was tested also by Lyme IgM/IgG Western Blot at Igenex, with the following results: positive IgM 18, 23-25, 34, 41, and 58-kDa bands; all IgG bands were negative or indeterminate. Since that time, the patient has continued to suffer from extreme fatigue, joint pain, cognitive problems, lymphadenopathy, and other symptoms.

Patient 6. In January 2010, the UNF Lab received a blood sample from a 38-year-old female patient living in Jacksonville, FL, who was being treated for chronic fatigue, headache, and neck and back pain. She had a long history of illness beginning in 2001. She stated that in 1981 she began taking camping trips throughout the Midwest, Northwest and southeastern U.S., where she encountered many tick bites. In 1991, while living in Cleveland, Ohio, she noticed a bull's-eye shaped rash on her right thigh that resolved after treatment with a few days of antibiotic.

In May 2001, while living in Greenville, South Carolina, she began to experience dizziness, eye strain, and poor vision in her left eye. A neuro-opthalmologist diagnosed left optic neuritis. A brain MRI was inconclusive for multiple sclerosis. Blood work ordered to test for a variety of other illnesses was unrevealing. However, the patient tested EIA positive (Quest Diagnostics) for Lyme antibodies at 1.31 (positive $>0.8$ ). A Lyme WB showed a reactive 41-kDa IgG band. During this period, she was treated with ciprofloxacin for a concurrent bladder infection, and subsequently the optic neuritis resolved. In July 2001, she had sudden onset of spinal pain, sciatica in her right hip and leg, headache, and fatigue. Thereafter she experienced worsening, migrating, shooting and burning pain, numbness, and tingling sensations 
throughout her body combined with impaired balance, light and sound sensitivity, tinnitus, and brain fog that soon rendered her unable to work.

In November 2001, she again tested positive by EIA (LabCorp) for Lyme antibodies (1.52), and a Lyme WB (LabCorp) showed reactive IgM 23 and IgG 41-kDa bands. An infectious disease specialist began several months of intravenous ceftriaxone and oral antibiotics for Lyme disease, yet her pain and many other symptoms continued. In June 2002, left optic neuritis returned, and again resolved several weeks later. During the next seven years, she experienced continued chronic fatigue, and pain in her neck, back, hips, and pelvis. She developed multiple food allergies and chronic gastrointestinal problems, and suffered recurrent bladder infections. During this time, she was treated off and on with oral antibiotics, and various herbal and vitamin/mineral supplements. In September 2009, a brain MRI showed increased plaque with T2 white matter in brain and corpus callosum/pons, and she was diagnosed with possible multiple sclerosis.

In January 2010, one of her doctors in Florida submitted a blood sample to the UNF Lab for research testing. Another sample was submitted in February 2010. The Jan 2010 sample was PCR positive, and the resulting DNA sequence (GenBank KC607893) was $99.8 \%$ identical (452/453 bp) to two reference strains of B. andersonii (strains MOD-5 GenBank AF264897 and SI-10 GenBank AF264883). The February 2010 sample was also PCR positive, and that DNA sequence (GenBank KC607894) was $99.2 \%$ identical to $B$. burgdorferi (2 bp mismatches with B31; 3 mismatches with JD1). Around the same time, neurology specialists in Jacksonville, FL also diagnosed multiple sclerosis and prescribed Copaxone, but the treatment was discontinued after one month due to major swelling at injection sites. The patient's symptoms waxed and waned over the next two years, as she was treated with rounds of different antibiotics, as well as integrative therapies including dietary modifications and herbs.

By early 2012, symptoms improved enough so that she began working again part-time. But, in November 2012, neck and back pain, dizziness, and fatigue worsened. The patient required a cushion to sit on, due to pain in her spine and right hip. She could not do overhead lifting, could not carry more than a light bag of groceries, and was unable to squat, kneel, or sit on the floor, making her work as an occupational therapist very difficult. In December 2012, another blood sample was submitted to the UNF lab. This sample also tested PCR positive, and that sequence was also $>99 \%$ identical to B. burgdorferi.
Patient 7. In early April 2010, Patient 7, a 50-yr-old male resident of Jacksonville, FL who worked as a homebuilder, removed an unengorged adult female $A$. americanum from his right hip and submitted the tick to the UNF Lab for identification and testing. The patient had not traveled outside the Jacksonville area for several weeks. Based on the lack of engorgement, the tick was estimated to have been attached for no more than 48 hours. Beginning approximately five days after the removal of the tick, the patient noticed an enlarging red lesion at the tick attachment site, and sought clinical evaluation. The lesion (Figure 2) was photographed multiple times as it progressed over the next two weeks. Meanwhile, the UNF Lab extracted DNA from the tick, and it tested positive for B. burgdorferi sensu lato flaB.

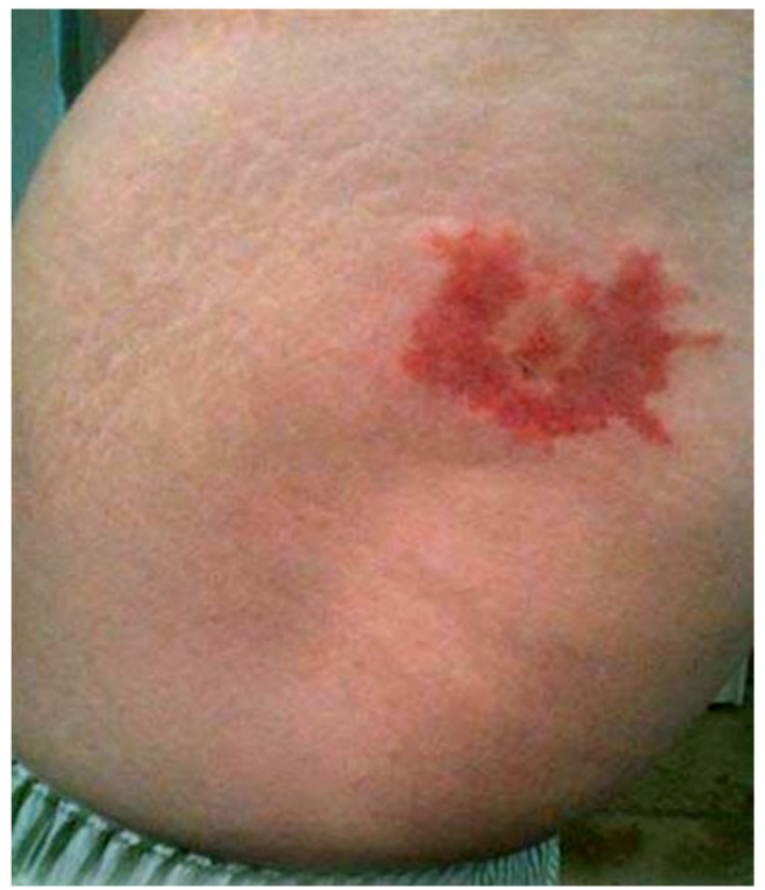

Fig 2. EM-like lesion on hip of Patient 7 following a confirmed female Amblyomma americanum attachment at the center of the lesion site.

The patient's primary care provider referred him to a dermatologist who submitted skin biopsy specimens to a pathologist and also to the UNF Lab. Blood and skin biopsy samples were cultured in BSK, but no spirochetes were observed. The patient's blood sample was PCR negative for B. burgdorferi flaB, but the skin biopsy specimen tested positive. The pathologist's report of microscopic analysis of the skin biopsy did not visualize spirochetes, but stated that pathologic changes were consistent with spirochete infection. The flaB DNA sequence obtained from the patient's attached lone star tick (GenBank KC607896) 
and the EM skin biopsy (KC607895) were 99.5\% identical (435/437 bp) to both B. burgdorferi B31 and JD1.

The patient began treatment with doxycycline upon initial clinical evaluation, and continued treatment for two months. A standard Lyme IgM/IgG Western Blot antibody test was performed (Quest Diagnostics) with samples obtained near the end of his treatment. The only antibody bands present were $\operatorname{IgM}$ and IgG 41-kDa. The patient was also tested at that time for Bartonella spp. antibodies, Ehrlichia chaffeensis, Anaplasma phagocytophilum, and Babesia microti (all IgM and IgG), all with negative results. The skin lesion at the tick bite site resolved in the weeks following initiation of treatment, and the patient did not experience any further signs or symptoms of illness. A second Lyme Western Blot test conducted four months later in August 2010 again showed antibody bands only to IgM and IgG 41-kDa protein.

Patient 8. Patient 8 was a 49 year-old male who lived in Fayette County, Georgia. He had a history of multiple tick bites acquired from around his home. In 2005, he developed a flu-like illness with a high fever, and was seen at an acute care center. A tick was found embedded in his scalp, with drainage seeping down the back of his head from the infected site. He was treated with a single dose of IM ceftriaxone and 10 days of oral doxycycline, with recovery from the infected bite site. Over the following years, he developed tremors, and became clumsy and prone to trip. In early 2008, he found the toe of his shoe wearing oddly because of gait disturbance. In spring 2009, his balance was noticeably off, and he sustained a fall, injuring his right foot and developing a right foot drop. By October of 2009, his back was visibly uneven and he sought chiropractic care. He also consulted a neurologist, who performed an EMG, and diagnosed amyotrophic lateral sclerosis (ALS).

By July 2010, he was unable to use his right arm, and two additional neurologists also diagnosed ALS. Because it was being explored as a treatment for ALS [55], IV ceftriaxone was recommended, but not initiated at that time. However, based on clinical history, and a 41-kDa IgG Lyme Western Blot band, a different physician diagnosed Lyme neuroborreliosis, and began treatment with azithromycin and fluconazole. In the fall of 2010 minocycline was started. He had severe low back pain with some degenerative disc disease on lumbar MRI, but otherwise was functioning neurologically, and was able to walk and work. However, by spring 2011, his neurologic status was again declining along with gait disturbance, worsening right foot drop, development of right foot plantar spasm, worsening fatigue, and exacerbation of low back pain. In July 2011, a second Lyme WB was nega- tive for any $\operatorname{IgM}$ or IgG bands. Dapsone was begun in August 2011.

In December 2011, he sought care by a different physician. At that time, he had pain in the knees, back, hips, and right shoulder. He was mostly wheelchair bound and required nearly full assistance to transfer. On physical exam, he demonstrated profound weakness in the trunk and arms (right arm greater than left). The right foot was erythematous, plantar flexed, and much colder than the left foot. Treatment was begun with mefloquine (for suspected babesiosis), tinidazole, and IV ceftriaxone. A blood sample submitted to the UNF Lab at this time was PCR positive and the flaB sequence (GenBank KC607897) was most similar to B. burgdorferi strains $(441 / 442 \mathrm{bp}=99.8 \%$ with JD1 and 439/442=99.3\% with B31).

During the following six months, the patient was treated with various antibiotics for suspected Lyme disease and bartonellosis. In June 2012, another blood sample submitted to the UNF Lab was PCR positive with DNA sequence confirmation for B. burgdorferi. During the treatment period, the patient's sense of general well-being, energy level, and pain levels improved. However, his neurologic status declined slightly, and he was still able to transfer only with full assistance. $\mathrm{He}$ is currently undergoing integrative manual therapy and physical therapy with marked improvement in low back and neck pain, and neck range of motion.

Patient 9. In May 2010, Patient 9, a 42-year-old male who lives in Jacksonville, FL was bitten by several nymph and adult lone star ticks while visiting the neighborhood in Fayette County, Georgia where Patients 5 and 8 live. In the weeks prior to that brief two-day trip to GA, he had not been in the woods around his house or noticed any ticks on his pets. He performed a thorough check and removed any attached ticks at the end of each day, except for one $A$. americanum nymph (species verified by UNF Lab) that was found and removed from his scalp. That tick was attached for a maximum of 24 to 48 hours. Unfortunately, it was partially destroyed during removal and was not testable. Four days later, the patient noticed swollen lymph nodes on the left side of his neck. During the next several days, he experienced vague, flu-like symptoms. Since he had never experienced any similar reaction from previous tick bites, which were numerous, he sought clinical evaluation from a physician. Venous blood samples acquired a few days after symptom onset tested negative at the UNF Lab by PCR for B. burgdorferi sensu lato, and no clinical laboratory tests for Lyme or other tickborne infections were ordered at that time. No EM lesions were observed at any of the tick attachment sites including his 
scalp, which was examined daily for the next two weeks. However, based on tick bite history and lymphadenopathy, he was treated with two weeks of doxycycline, followed by 10 days of levofloxacin. The mild symptoms and lymphadenopathy resolved quickly, and he appeared well for the next few months.

In November 2010, the patient began to experience chronic, unexplainable fatigue that prevented him from his normal exercise routine, and began to impair his work productivity. In December 2010, he experienced sudden onset of severe, migraine-like headache that became less severe in subsequent days, but remained almost constant for the following three weeks. During that time, he also experienced a sense of pressure in the head and sinuses (despite no evidence of sinus congestion), stiff neck, continued fatigue, difficulty concentrating, and a "fuzzy" or "ha$z^{\prime \prime}$ cognitive sensation. The patient never before experienced this clinical syndrome.

At this point, still in December, he sought additional clinical evaluation. Newly drawn venous whole blood samples, and dried blood spot (DBS) samples obtained from ear lobe scrapings [56] and lancet sticks, were tested by PCR at the UNF Lab. Serum samples were also submitted to Labcorp for a Lyme IgM/IgG Western Blot. The patient's Lyme Western Blot result showed only a 41-kDa IgM band. Multiple DNA extractions from the December whole blood samples were PCR negative for B. burgdorferi. However, one ear lobe scrape and one ear lobe stick DBS sample were PCR positive for B. burgdorferi sensu lato $\mathrm{flaB}$. The $\mathrm{flaB}$ sequence (Genbank KC607898) was $99.3 \%(427 / 430 \mathrm{bp})$ identical to $B$. andersonii strains MOD-5 and SI-10.

Beginning in January 2011, the patient was treated for one month with doxycycline, clarithromycin, and atovaquone (the latter for suspected concurrent babesiosis). Thereafter, he was treated with metronidazole, clarithromycin, and amoxicillin in pulsed fashion for approximately two months. During that time, the patient's symptoms resolved, normal energy levels returned, and he felt well for several months. A follow up Lyme WB at Labcorp conducted in March 2011 showed no IgM or IgG bands. In November 2011, fatigue returned, accompanied by occasional twitching of multiple body parts, particularly the eyelid and upper lip, along with neck soreness and stiffness, occasional mild burning sensation of the eyes, and pressure in the sinuses. In December, headache returned and remained constant. New DBS samples were obtained from ear lobes and finger sticks. Ear lobe DBS extracts were PCR negative, but finger stick DBS extracts were PCR positive for B. burgdorferi sensu lato on multiple occasions. The new flaB sequence (GenBank KC607899) was 99.8\% identical (412/413 bp) to B. burgdorferi B31.

A third Lyme IgM/IgG WB test was ordered in January 2012, this time from IgeneX, Inc. It showed a positive IgM 41 and IgG 41, 39, and 58-kDa bands. The patient was treated for another three months with combination oral antibiotics for both babesiosis and borreliosis, and his symptoms improved significantly. In May 2012 a fourth Lyme WB test was done (Labcorp), which resulted in no positive bands reported. PCR results for a new whole blood sample drawn at the same time were negative for B. burgdorferi sensu lato. However, in June 2012, another finger stick DBS sample was PCR positive, and the resulting DNA sequence was identical to the most recent one, again indicating B. burgdorferi infection. After several months of feeling mostly well and with improved energy levels, except for occasional headache, fatigue, brain fog, and neck stiffness, in November 2012 the patient again experienced a bout of increased fatigue. In December 2012 another venous blood sample was tested by PCR, and both whole blood and plasma extracts tested positive for B. burdorferi flaB; the resulting sequence (GenBank KC607900) again differed by one bp from strain B31.

Patient 10. In December 2012, a blood sample was submitted to the UNF Lab from a 69-year-old male resident of Jacksonville, FL. The patient was a retired college professor who had lived for the past 32 years in Florida. The patient had uncertain history of tick bite. Medical records showed a history of carpal tunnel syndrome, diverticulosis, plantar fasciitis, renal insufficiency, Dupuytren's contracture of the hand, and chronic prostatitis, the latter for which he had been treated for several years with daily doxycycline. His recent medical history included the following. In April 2012, he saw his family physician complaining of pain in his knees and hips, and was diagnosed with degenerative joint disease. In May 2012, he was treated with azithromycin and cefuroxime axetil for a lingering upper respiratory infection with cough. In October 2012, he again saw his family physician for a chronic sore throat, cough, and upper respiratory infection, which was again treated with azithromycin. At that visit, his wife noted that she had recognized in him a recent, but significant, cognitive decline and a few episodes of disorientation. This prompted neurological evaluation by specialists in Jacksonville, and included comprehensive physical exam, brain EEG and MRI studies, and microbiological testing.

Cerebrospinal fluid (CSF) protein was elevated at 51 (normal $1-45 \mathrm{mg} / \mathrm{dL}$ ); CSF 14-3-3 protein was high at $5.9 \mathrm{ng} / \mathrm{mL}$ (reference $<1.5 \mathrm{ng} / \mathrm{mL}$ ), which was 
described as compatible with but not diagnostic of Creutzfeldt-Jakob disease (CJD). Multiple tests were conducted to rule out bacterial, fungal, and viral infections. A brain MRI showed cortical ribboning. Brain EEG showed abnormal diffuse intermittent slowing over both hemispheres, seemingly worse on the left side. Diagnoses considered by the patient's neurologist were spongiform encephalopathy/prion disease, viral encephalitis, or some other inflammatory condition. The ultimate diagnosis given to the patient was CJD, with a realistic prognosis of only months, with steady decline.

Several weeks passed without any noticeable cognitive or motor function change. In December, seeking to explore other possible explanations, one of the patient's primary care physicians ordered a Lyme screen test (IFA) and Western Blot (IgeneX), and submitted samples to the UNF Lab for PCR testing. Several plasma DNA extracts tested positive by Lyme Borrelia flagellin PCR. The DNA sequences from two samples were identical (GenBank KC607901), and were $>99 \%$ identical with reference strains of $B$. burgdorferi (2 bp mismatches with JD1; 3 mismatches with B31). The IFA test was equivocal (titer 1:40). The
WB showed IgM 31, 41, and 58-kDA bands, and IgG $18,30,34,41$, and 58-kDa bands. Five months after the patient's CJD diagnosis, he had still not declined physically or cognitively, and was pursuing antibiotic treatment for Lyme disease.

DNA sequence analysis. Over the $f l a B$ sequence fragment analyzed, the human patient $B$. burgdorferi strains differed from B31 or JD1 by a minimum of 0-3 bp. Borrelia americana SCW-30h differs from B31 by seven bp (BLAST result $423 / 430=98.4 \%$ ). The human patient $B$. americana strains differed from $B$. americana SCW-30h by only one bp, and from B31 and other $B$. burgdorferi strains by a minimum of eight $\mathrm{bp}$. The Patient $1 \mathrm{~B}$. andersonii strain sequence was identical to a few reference strains of that species in Genbank (for example, SI-10). The Patient 6 B. andersonii sequence differed from reference strain $B$. andersonii by one bp, and the Patient $9 B$. andersonii sequence differed from reference strains of $B$. andersonii by a minimum of three bp. The phylogenetic tree (Fig. 3) shows that flaB gene sequences derived from blood, tissue, or ticks from human patients in Florida and Georgia clearly clustered with reference strains of $B$. burgdorferi sensu stricto, B. americana, or B. andersonii.

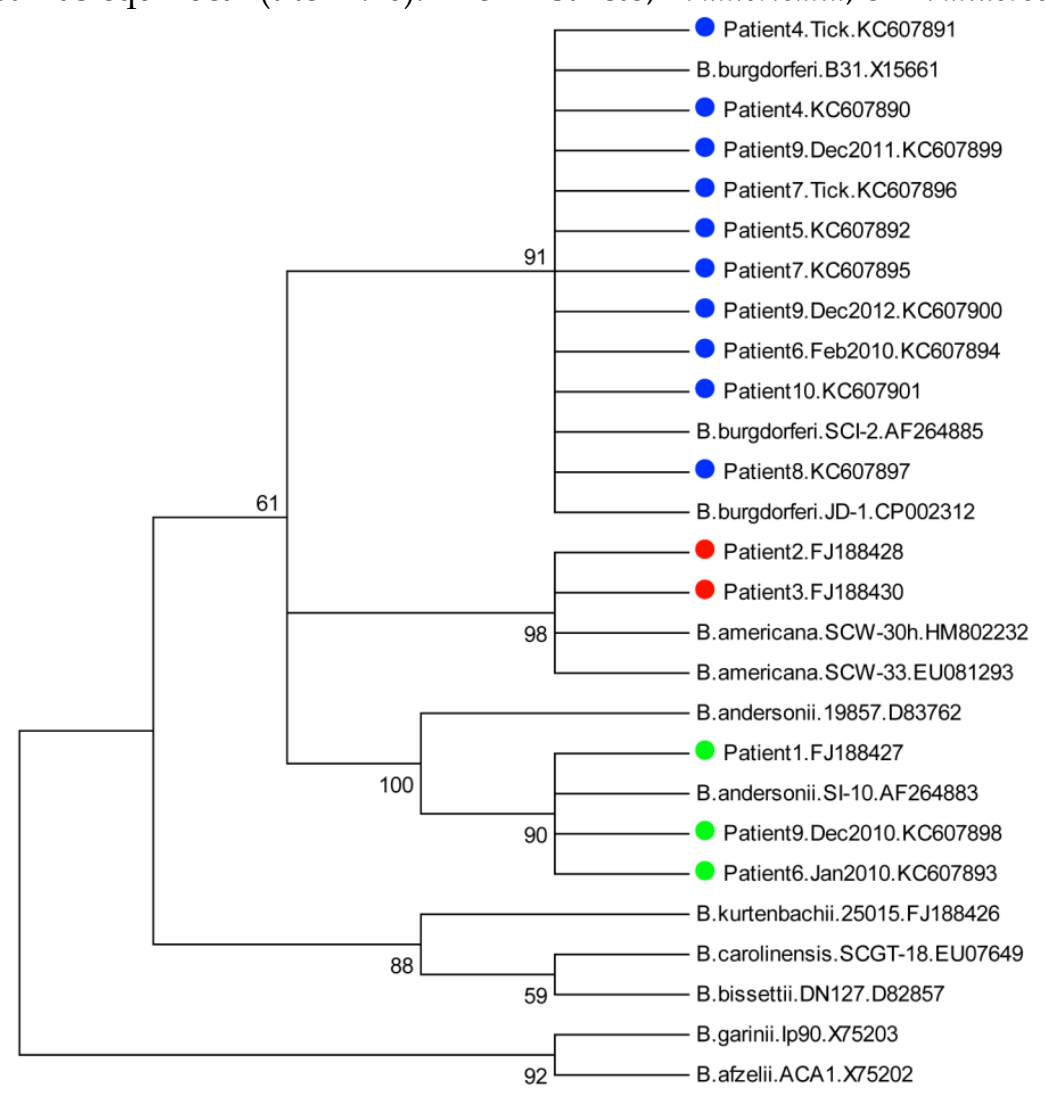

Fig 3. Neighbor joining bootstrap phylogenetic tree based on a comparison of flagellin (flaB) gene sequences obtained from human patients and ticks in Florida and Georgia with Borrelia burgdorferi sensu lato reference strains. The percentage of replicate trees in which the associated taxa clustered together in the bootstrap test ( 1,000 replicates) are shown at the branch nodes. Evolutionary distances were computed using the Maximum Composite Likelihood method. All positions containing gaps and missing data were eliminated. There were a total of 355 positions in the final data set. 


\section{Discussion}

Only two studies have reported culture isolation of $B$. burgdorferi spirochetes from human patients in the southern U.S. Rawlings et al. [23] isolated Borrelia spirochetes from 14 patients in Texas. Several of the isolates were determined to be Lyme Borrelia spirochetes based on reactivity with ospA monoclonal antibody H5332 specific for B. burgdorferi. Felz et al. [22] isolated a B. garinii strain from a patient with known $I$. scapularis exposure in southern Georgia (USA), but he had also traveled in Europe in the weeks prior to onset of EM, thus confounding attempts to exactly determine the exposure location. To date, attempts by the UNF Lab to isolate Borrelia from human patients in the southern U.S. presenting with Lyme-like signs and symptoms have been unsuccessful. In this study we failed to isolate spirochetes from blood and skin biopsies from several patients from Florida and Georgia, despite identifying B. burgdorferi sensu lato DNA in their blood, skin, or previously attached ticks. This may have been due to using a low volume of patient fluid samples, a low number of spirochetes in the samples that could not be detected via culture, or perhaps the strains infecting patients in this region do not grow well in BSK-H medium. Culture isolation in BSK medium is known to be selective for specific genotypes of B. burgdorferi sensu lato [57].

Based on extensive experience in testing samples from wild vertebrates and ticks in the southern U.S. for the presence of B. burgdorferi sensu lato, we chose to screen patient samples using highly sensitive nested PCR assays targeting a portion of the 41-kDa chromosomal flagellin $(\mathrm{flaB})$ gene. This approach was used in a previous study of patients with EM lesions in Georgia and South Carolina, where a different, but also highly sensitive nested flaB PCR assay was positive for $22 \%$ of patients [22]. Unfortunately, that study did not provide DNA sequence data for the amplified $f l a B$ fragments, preventing genospecies determination. Our B. burgdorferi sensu lato species designations were based upon analysis of a central portion of the flaB gene. Borrelia burgdorferi sensu lato species typing based upon analysis of this gene region has been proven reliable [58-61] and in agreement with species typing based on comparing sequences from other single genes (e.g., 16SrRNA, groEL), multi-locus gene analyses, and other methods like randomly amplified polymorphic DNA (RAPD) analyses [7, 62-65]. This gene has also been shown to be a more sensitive PCR target for B. burgforferi sensu lato compared to other commonly targeted genes $[61,66]$.

We obtained DNA sequences from two patients that were highly similar (greater than $99 \%$ ) to the $B$. americana SCW-30h strain flaB sequence. Borrelia americana strains are most similar to $B$. burgdorferi sensu stricto strains in the portion of the $f l a B$ gene analyzed in this study, but they clearly cluster separately in phylogenetic analyses [20]. Our findings represent the first report implicating $B$. americana in human infection, and raise the question of whether $B$. americana strains are responsible for other human cases of Lyme-like illness in the southern USA and elsewhere, since strains of this group have also been identified in California [9]. Notably, blood samples obtained from Patient 2 in 2004 and 2009, during which time she experienced continuous symptoms consistent with persistent Lyme borreliosis, both tested positive for B. americana DNA. This suggests that some B. americana strains may be capable of establishing persistent, treatment-resistant borreliosis. The B. americana infection for Patient 3 was diagnosed early, based on the appearance of a typical EM lesion, and appeared to resolve without complication following a total of seven weeks of doxycyline treatment.

We amplified B. andersonii DNA from blood obtained from Patient 1 more than a month after onset of a disseminated and persistent erythema migrans-like rash, despite the lack of detectable antibody via EIA at the time the sample was obtained. Based on comparison of a portion of the $f l a B$ gene, this strain was $100 \%$ identical to previously described strains of B. andersonii that were cultivated in the laboratory of Dr. James H. Oliver at Georgia Southern University [64]. After initial onset Patient 1 continued to experience symptoms for many years that were possibly associated with ongoing borreliosis. The first flaB gene sequences obtained from Patients 6 and 9 were also most similar, but not identical, to reference strains of $B$. andersonii that have never been cultivated in the UNF Lab. Therefore, these data represent the first evidence of $B$. andersonii in patients with Lyme borreliosis.

Positive PCR results were obtained for Patient 6 (B. andersonii or B. burgdorferi) on samples taken nearly three years apart, for Patient 8 (B. burgdorferi) on two samples taken seven months apart, and for Patient 9 (B. andersonii or B. burgdorferi) on four samples spanning two years. However, it should be reiterated that Patients 6 and 9 each tested positive for B. andersonii only once; they then tested positive for sequence confirmed B. burgdorferi multiple times thereafter. It is not known if the $B$. andersonii infections were cleared with antibiotics, or if the patients continued to have multi-species Lyme borreliosis infection. Nevertheless, Patients 1, 2, 6, 8, and 9 experienced recurrent or constant symptoms lasting months or years, and all underwent periods of antibiotic treatment between the times they were shown to have B. burgdorferi sensu 
lato DNA in their bodies.

It is presently not known if all B. burgdorferi sensu lato genospecies are pathogenic to humans. Certain B. burgdorferi sensu lato species may exist in ecological niches involving reservoir hosts and arthropod vectors that humans rarely encounter; thus humans may rarely if ever be infected by these strains due to lack of incidental contact with their transmission cycles, rather than because the strains lack pathogenicity. In Europe, B. garinii, B. afzelii, and B. burgdorferi are recognized as agents of Lyme disease [67]. In the U.S., B. burgdorferi has been considered the only pathogenic species [67] until recently when some B. bissettii-like strains were identified in serum of human patients in California using molecular methods [10]. Our evidence of human B. americana and B. andersonii infections therefore further challenges the notion that only B. burgdorferi (sensu stricto) is associated with Lyme disease in the U.S. It seems probable that Lyme disease in the U.S. is similar to the situation in some areas of Europe and Asia, in that multiple $B$. burgdorferi sensu lato species in addition to $B$. burgdorferi may be associated with human disease.

The lack of more precise epidemiologic information for Patient 2 in this study limits our ability to draw exact conclusions regarding the location of infectious exposure for that case. It is possible that the patient acquired infection while visiting or living in states other than Florida or Georgia, or outside the U.S. Patient 6 had extensive outdoor activity and tick bite history in multiple regions of the U.S. The location of her infective tick bite is not known, and over the years she sought evaluation and treatment in different states. Tick bite exposure location for Patient 10 was also uncertain. These cases were included in the present paper because at the time samples were submitted to the UNF Lab, all were living in, and being evaluated clinically or being treated, in Florida or Georgia. This demonstrates that, regardless of where a patient might have been infected, one can present with Lyme disease symptoms in other places, including areas not considered endemic for the disease.

Several patients described in this study with no travel history or tick exposure outside the study area (Patients 1, 3, 4, 5, 7, 8, 9) likely acquired their tickborne infections in Florida or Georgia. Furthermore, it should be noted that these cases represent a small fraction $(<10 \%)$ of PCR and DNA sequence confirmed cases the UNF Lab has identified in the southern U.S. (unpublished data). Evidence of additional cases will be presented and discussed in future papers. Therefore, Lyme disease may not be rare in the study region. The cases described in the present study may represent a broad spectrum of Lyme borreliosis that has heretofore been significantly under-recognized, under-diagnosed, and under-reported in southern states.

We found no evidence of false positive PCR results from DNA contamination/artifacts during this study, and samples from control patients did not test positive for Lyme Borrelia DNA. Strains of B. americana and $B$. andersonii most similar to those we identified in human patients [64] were not cultivated in the UNF Lab. The B. burdorferi sensu lato flaB DNA sequence differences among human patient samples, and as compared to the positive control sample used in PCR testing, along with some unique nucleotide differences confirmed in several of the human strains obtained in this study as compared to reference strains (data not shown), argue against DNA contamination as a plausible explanation of the study findings. Despite the similarity in sequences derived from human patients in this study to reference strains in the portion of the $f l a B$ gene analyzed, however, it is possible that southern strains are still significantly different from northeastern $B$. burgdorferi and other well-characterized B. burdorferi sensu lato strains in other individual genes (e.g., certain plasmids), or over their entire genomes.

Several patients in this study were tested for Lyme (B. burgdorferi) antibodies using standard tests at clinical laboratories. Yet, based on U.S. Centers for Disease Control surveillance interpretation criteria [68], nearly all results would be considered negative. Four of six patients had equivocal or positive EIA or IFA screening tests, but only Patient 10 in our study may have met the current 2-tier testing standard criteria for Lyme seropositivity. Patient 1's EIA sample was submitted approximately two months after she received the putatively infectious tick bite, and at least one month after onset of a widely disseminated rash involving multiple small EM-like lesions. One would expect that enough time had passed since initial infection for her to develop detectable antibodies if the test were capable of identifying them. Patient 5 had an equivocal EIA, and a WB with five IgM bands, but the WB results were obtained a year after the EIA test; because her illness onset was many months prior to this test, the test result would be interpreted based on IgG band criteria (minimum of five bands required for positive result). Patient 6 had two positive EIA tests, but concurrent WB tests failed to show enough antibody bands to be considered positive. Lyme WB tests were conducted on Patient 7 at approximately one and four months after onset of a distinct EM lesion following his tick bite, and both showed only 41-kDa $\operatorname{IgM}$ and IgG bands. Patient 8 had only the IgG 41-kDa band. Patient 9's first Lyme WB (Jan 2011) was per- 
formed approximately seven months after the implicated tick bite(s) and initial symptom onset, and it also showed only the IgM 41-kDa band. A second WB test conducted at that same laboratory (Labcorp) two months later failed to detect any antibodies. In January 2012, the third WB test conducted at a different lab (IgeneX) showed one IgM and three IgG antibodies, more indicative of actual Lyme disease infection, yet a fourth WB test (Labcorp) months later (May 2012) was completely negative, even though additional PCR tests for B. burgdorferi sensu lato were positive in June and December of that year. Only Patient 10 had a suggestive (equivocal) IFA and concurrently positive WB result, which in this case included three $\operatorname{IgM}$ and five $\operatorname{IgG}$ reactive bands. However, two (31 and $58-\mathrm{kDa}$ ) of his three reactive IgM bands, and one of his five IgG bands (34-kDa ospB protein), are not considered in the standard interpretation criteria used in the U.S. Despite this, all the patients in this study had evidence of sequence confirmed Lyme Borrelia DNA in their bodies concurrent with signs or symptoms consistent with early or late stage borreliosis. This highlights the need for health care providers everywhere to be properly trained to recognize the signs and symptoms of various stages of Lyme disease, to understand the strengths and limitations of different laboratory tests, and to include Lyme disease in the differential diagnosis in the presence of a consistent clinical history.

Several possible reasons for lack of development of, or detection of, Lyme antibodies have been described [69-70]. The PCR and DNA sequence confirmed $B$. burgdorferi sensu lato infections described here suggest that Lyme borreliosis patients in the study area may present with antibody profiles that differ significantly from what is considered diagnostic for Lyme disease in other areas. It is possible that genetic variability among southern $B$. burgdorferi sensu lato strains may play a role in the lack of consistently detectable antibodies to specific proteins besides the 41-kDa flagellin, which was commonly observed among patients in this study and others conducted in the southern U.S. [22, 35, 37]. Therefore, in cases where there is compelling evidence of early stage tickborne infection based upon clinical presentation and history of tick exposure, careful consideration should be given to initiating antibiotic treatment without delay pending a positive antibody or other clinical confirmation test result [71]. It is possible that some negative or equivocal B. burgdoreri EIA or WB antibody test results, interpreted based upon current guidelines, occur due to infection with B. burgdorferi sensu lato strains other than those that the clinical diagnostic tests and their current interpretation crite- ria were developed to identify. Clearly, what is needed is a comprehensive analysis of the ability of current standard antibody tests to correctly identify infection with the diverse B. burgdorferi sensu lato species endemic to North America, and these studies need to include representative strains of different species from different geographic regions. Furthermore, they need to include representative healthy control patients to accurately assess the true rate of false positive antibody results.

Patients in this study were diagnosed with different syndromes, including CFS, fibromyalgia, lupus, MS, ALS, and CJD. The exact causes of these conditions are still unknown or not completely understood. These syndromes are diagnosed primarily based on exclusion of other likely explanations or limited objective laboratory evidence. These syndromes in our study patients may not have been caused by concurrent Lyme borreliosis. However, because symptoms of different chronic diseases can overlap with Lyme disease, especially neuroborreliosis, Lyme disease should be considered in evaluation of other patients with a history of tick exposure that present with symptoms consistent with the aforementioned syndromes.

The tick species responsible for transmission of B. burgdorferi sensu lato to several patients in this study were not known conclusively. Patient 1 from Florida did not seek care until approximately one month after onset of EM in late March following a tick bite presumably acquired in either February or early March. Both A. americanum (nymphs and adults) and adult $I$. scapularis are active in northern Florida at that time [72]. Florida Patient 3 had onset of EM approximately one week following tick exposure in early November, when adult I. scapularis are active [72]. Although this patient reported finding ticks on her clothing while walking through the woods the day of the putative exposure, she did not recall an attached tick, despite what resembled a tick bite punctum in the center of the EM lesion (see Fig. 1). The only other evidence pointing towards I. scapularis in her case is the adult male tick (Is-TSP1) collected at the same park approximately one month after the patient was exposed to ticks there, from which we also obtained DNA evidence of a B. americana strain. The tick species implicated in transmission of B. burgdorferi or B. andersonii strains to Patients $4,5,7,8$, and 9 was $A$. americanum. Furthermore, due to the abundance of $A$. americanum at the Fayette County, GA residential site where Patients 5, 8, and 9 were believed to have been infected, along with our finding $B$. burgdorferi sensu lato DNA in several host seeking A. americanum collected from this site (unpublished data), we suspect 
that this tick species may have been responsible for the cases with tick bite exposure at that location. Further studies and testing of ticks at this site are in progress.

Due to their abundance, aggressive human biting habit, and seasonal association with many Lyme disease cases in the southern U.S., including several described in this study, the vectorial role of lone star ticks in transmitting B. burgdorferi sensu lato deserves further consideration. Earlier laboratory transmission experiments of the ability of lone star ticks to acquire, maintain, and transmit B. burgdorferi spirochetes necessarily used only a few cultivable strains isolated from rodents [73-75]. It is possible that lone star ticks or other human biting tick species can transmit Lyme group Borrelia strains that naturally infect host animals other than rats or mice (e.g, rabbits or birds). One study reported culture isolation of $B$. burgdorferi from several lone star ticks, a single A. maculatum (Gulf Coast tick), and a cat flea from Texas [19]. A subsequent study of vector competence of three human biting tick spp. found those five isolates to be non-infectious to the mice used in that study, thus preventing use of those isolates in that study's tick transmission experiments [74]. Those authors postulated that the original isolates may have resulted from culture contamination of the primary isolates with a high passage strain of $B$. burgdorferi, which might explain the isolates' loss of infectivity, as has been shown in other studies [75]. However, considering the difficulty in isolating and sometimes maintaining $B$. burgdorferi sensu lato in culture, the authenticity of the original isolates as reported is still debatable [19].

In a previous study, we identified B. burgdorferi DNA in host seeking lone star ticks in Florida [45], and we continue to find B. burgdorferi and also B. andersonii strains in lone star ticks tested by PCR from Florida and Georgia (unpublished data). Several other studies have reported B. burgdorferi DNA in lone star ticks using Lyme Borrelia specific PCR assays [77-79]. Therefore, pending more comprehensive studies, $A$. americanum should not be ruled out as possible vectors of southern strains of B. burgdorferi sensu lato to humans.

Much more research is necessary to conclusively determine the reservoir hosts and arthropod vectors responsible for transmission of $B$. burgdorferi sensu lato in natural cycles and to humans in different geographic areas. Immature stages of I. scapularis, the accepted vector of Lyme Borrelia in the eastern U.S., feed upon birds as well as lizards and mammals, and A. americanum larvae and nymphs also feed on birds and several mammals including gray squirrels, rabbits, and deer [80]. Borrelia americana strains were ini- tially isolated from ticks removed from a Carolina wren [9]. Most B. andersonii strains isolated to date came from rabbits or I. dentatus removed from them [64], and I. dentatus also commonly feed on birds [81]. Therefore, until more evidence indicates specific reservoir or vector species for human pathogenic Lyme Borrelia strains in the southern U.S., investigating a broad diversity of vertebrates and ticks will likely lead to more relevant discoveries that improve our understanding of Lyme disease ecology in the region.

The inability to previously identify a likely cause of the Lyme-like signs and symptoms experienced by patients residing in southern states led to investigations of potential agents besides Lyme group Borrelia spp. The subsequent identification of the relapsing fever group species B. lonestari in A. americanum [24] provided circumstantial evidence supporting an alternative cause for the phenomenon that came to be known as STARI. However, besides a single human case of STARI associated with the presence of $B$. lonestari DNA detected in the tick and human EM lesion skin biopsy sample [32], no additional evidence has been published to date that supports $B$. lonestari as the cause of STARI. Moreover, in the present study we confirmed B. burgdorferi sensu lato DNA in four patients with signs or symptoms of Lyme borreliosis following confirmed lone star tick bites. Our findings suggest that some cases of STARI resembling Lyme borreliosis in the southern U.S. may be attributable to previously undetected Lyme Borrelia strains, and thus represent cases of actual Lyme borreliosis rather than a separate disease entity or tick hypersensitivity reactions.

We continue to obtain and test fluid and tissue specimens and attached ticks from human subjects in the southern U.S. presenting with signs and symptoms indicative of both early and late stage borreliosis. We hope to further clarify the ongoing medical query of the primary vectors and pathogens responsible for Lyme-like illness in the southern U.S., and in other areas of the country traditionally considered as non-endemic for Lyme disease. Additional research is also needed to improve our understanding of Lyme Borrelia strains potentially associated with persistent infection and associated clinical manifestations, and to improve routinely available clinical diagnostic tests to identify $B$. burgdorferi sensu lato strains associated with human illness.

\section{Acknowledgments}

This research was supported in part by a University of North Florida Brooks College of Health Dean's Professorship grant and a research grant from the Lyme Disease Association (Jackson, New Jersey) 
awarded to KLC. Additional funding was provided by the Northeast Florida Lyme Association, Georgia Lyme Disease Association (GALDA), the Community Foundation of Jacksonville, and gifts by numerous private individuals to Dr. Clark's UNF research foundation account. Technical assistance in coordinating sample and data collection from several patients from Georgia was also provided by GALDA. The authors are grateful to all the human subjects who agreed to participate in the study, and the clinicians who provided samples for the laboratory research testing.

\section{Competing Interests}

The authors confirm that they have no conflicts of interest that could bias any aspect of the present paper. They have no financial interests in, relationships with, and have received no funding from, any clinical laboratories or test kit or reagent manufacturers mentioned in the paper.

\section{References}

1. Bacon R, Kugeler K, Griffith K, et al. Centers for Disease Control and Prevention, Lyme disease-United States. MMWR 2007; 56(23): 573-576.

2. Johnson RC, Schmid GP, Hyde FW, et al. Borrelia burgdorferi sp. nov.: etiologic agent of Lyme disease. Int J Syst Bacteriol. 1984; 34(4): 496-497.

3. Marconi RT, Liveris D, Schwartz I. Identification of novel insertion elements, restriction fragment length polymorphism patterns, and discontinuous 23S rRNA in Lyme disease spirochetes: phylogenetic analyses of rRNA genes and their intergenic spacers in Borrelia japonica sp. nov. and genomic group 21038 (Borrelia andersonii sp. nov.) isolates. J Clin Microbiol. 1995; 33(9): 2427-2434

4. Margos G, Vollmer SA, Cornet M, et al. A new Borrelia species defined by multilocus sequence analysis of housekeeping genes. App Env Microbiol. 2009; 75(1): 5410-5416

5. Margos G, Hojgaard A, Lane RS, et al. Multilocus sequence analysis of Borrelia bissettii strains from North America reveals a new Borrelia species, Borrelia kurtenbachii. Ticks TickBorne Dis. 2010; 1(4): 151-158.

6. Postic D, Marti Ras N, Lane RS, et al. Expanded diversity among Californian Borrelia isolates and description of Borrelia bissettii sp. nov. (formerly Borrelia group DN127). J Clin Microbiol. 1998; 36(12): 3497-3504.

7. Postic D, Garnier M, Baranton G. Multilocus sequence analysis of atypical Borrelia burgdorferi sensu lato isolates-description of Borrelia californiensis sp. nov., and genomospecies 1 and 2. Int J Med Microbiol. 2007; 297(4): 263-271.

8. Rudenko N, Golovchenko M, Grubhoffer L, et al. Borrelia carolinensis sp. nov., a new (14th) member of the Borrelia burgdorferi sensu lato complex from the southeastern region of the United States. J Clin Microbiol. 2009; 47(1): 131-141.

9. Rudenko N, Golovchenko M, Lin T, et al. Delineation of a new species of the Borrelia burgdorferi sensu lato complex, Borrelia americana, sp. nov. J Clin Microbiol. 2009; 47(12): 3875-3880.

10. Girard YA, Fedorova N, Lane RS. Genetic Diversity of Borrelia burgdorferi and detection of B. bissettii-like DNA in serum of north-coastal California residents. J Clin Microbiol. 2011; 49(3): 945-954.

11. Burgdorfer W, Barbour AG, Hayes SF, et al. Lyme disease-a tick-borne spirochetosis? Science. 1982; 216(4552): 1317-1319.

12. Brown RN, Lane RS. Reservoir competence of four chaparral-dwelling rodents for Borrelia burdorferi in California. Am J Trop Med Hyg. 1996; 54(1): 84-91.

13. Levine JF, Wilson ML, Spielman A. Mice as reservoirs of the Lyme disease spirochete. Am J Trop Med Hyg. 1985; 34(2): 355-360.

14. Apperson CS, Levine JF, Evans TL, et al. Relative utilization of reptiles and rodents as hosts by immature Ixodes scapularis (Acari: Ixodidae) in the coastal plain of North Carolina, USA. Exp Appl Acarol. 1993; 17(10): 719-731.
15. Durden LA, Oliver JH Jr, Banks CW, et al. Parasitism of lizards by immature stages of the blacklegged tick, Ixodes scapularis (Acari: Ixodidae). Exp Appl Acarol. 2002; 26(3-4): 257-266.

16. Wright SA, Lane RS, Clover JR. Infestation of the southern alligator lizard (Squamata: Anguidae) by Ixodes pacificus (Acari: Ixodidae) and its susceptibility to Borrelia burgdorferi. J Med Entomol. 1998; 35(6): 1044-1049.

17. Durden LA, McLean RG, Oliver JH Jr, et al. Ticks, Lyme disease spirochetes, trypanosomes, and antibody to encephalitis viruses in wild birds from coastal Georgia and South Carolina. J Parasitol. 1997; 83(6): 1178-1182.

18. Oliver JH Jr, Lin T, Gao L, et al. An enzootic transmission cycle of Lyme borreliosis spirochetes in the southeastern United States. Proc Nat Acad Sci USA. 2003; 100(20): 11642-11645.

19. Teltow GJ, Fournier PV, Rawlings JA. Isolation of Borrelia burgdorferi from arthropods collected in Texas. Am J Trop Med Hyg. 1991; 44(5): $469-474$.

20. Clark K, Hendricks A, Burge D. Molecular identification and analysis of Borrelia burgdorferi sensu lato in lizards in the southeastern United States. Appl Env Microbiol. 2005; 71(5): 2616-2625.

21. Swanson KI, Norris DE. Detection of Borrelia burgdorferi DNA in lizards from southern Maryland. Vector Borne Zoonotic Dis. 2007; 7(1): 42-49.

22. Felz MW, Chandler FW Jr, Oliver JH Jr, et al. Solitary erythema migrans in Georgia and South Carolina. Arch Dermatol. 1999; 135(11): 1317-1326.

23. Rawlings JA, Fournier PV, Teltow GJ. Isolation of Borrelia spirochetes from patients in Texas. J Clin Microbiol. 1987; 25(7): 1148-1150.

24. Barbour AG, Maupin GO, Teltow GJ, et al. Identification of an uncultivable Borrelia species in the hard tick Amblyomma americanum: possible agent of a Lyme disease-like illness. J Infect Dis. 1996; 73(2): 403-409.

25. Bacon RM, Gilmore RD Jr, Quintana M, et al. DNA evidence of Borrelia lonestari in Amblyomma americanum (Acari: Ixodidae) in southeast Missouri. J Med Entomol. 2003; 40(4): 590-592.

26. Burkot TR, Mullen GR, Anderson R, et al. Borrelia lonestari DNA in adult Amblyomma americanum ticks, Alabama. Emerg Infect Dis. 2001; 7(3): 471-473.

27. Moore VA IV, Varela AS, Yabsley MJ, et al. Detection of Borrelia lonestari, putative agent of southern tick-associated rash illness, in white-tailed deer (Odocoileus virginianus) from the southeastern United States. J Clin Microbiol. 2003; 41(1): 424-427.

28. Stegall-Faulk T, Clark DC, Wright SM. Detection of Borrelia lonestari in Amblyomma americanum (Acari: Ixodidae) from Tennessee. J Med Entomol. 2003; 40(1): 100-102.

29. Stromdahl EY, Williamson PC, Kollars TM Jr, et al. Evidence of Borrelia lonestari DNA in Amblyomma americanum (Acari: Ixodidae) removed from humans. J Clin Microbiol. 2003; 41(12): 5557-5562.

30. Taft SC, Miller MK, Wright SM. Distribution of borreliae among ticks collected from eastern states. Vector Borne Zoonotic Dis. 2005;5(4): 383-389.

31. Varela AS, Moore VA, Little SE. Disease agents in Amblyomma americanum from northeastern Georgia. J Med Entomol. 2004; 41(4): 753-759.

32. James AM, Liveris D, Wormser GP, et al. Borrelia lonestari infection after a bite by an Amblyomma americanum tick. J Infect Dis. 2001; 183(12): 1810-1814.

33. Wormser GP, Masters E, Liveris D, et al. Microbiologic evaluation of patients from Missouri with erythema migrans. Clin Infect Dis. 2005; 40(3): 423-428.

34. Masters EJ, Grigery CN, Masters RW. STARI, or Master's disease: lone star tick-vectored Lyme-like illness. Infect Dis Clin N Am. 2008; 22(2): 361-376.

35. Kirkland KB, Klimko TB, Meriwether RA, et al. Erythema migrans-like rash illness at a camp in North Carolina: a new tick-borne disease? Arch Int Med. 1997; 157(22): 2635-2641.

36. Hansen K, Hindersson P, Pedersen NS. Measurement of antibodies to Borrelia burgdorferi flagellum improves serodiagnosis of Lyme disease. J Clin Microbiol. 1988; 26(2): 338-346.

37. Masters E, Granter S, Duray $\mathrm{P}$, et al. Physician-diagnosed erythema migrans and erythema migrans-like rashes following lone star tick bites. Arch Dermatol. 1998; 134(8): 955-960.

38. Clark KL. Anaplasma phagocytophilum in small mammals and ticks in northeast Florida. J Vect Ecol. 2012; 37(1): 262-268.

39. Fang QQ, Mixson TR, Hughes M, et al. Prevalence of the agent of human granulocytic ehrlichiosis in Ixodes scapularis (Acari: Ixodidae) in the coastal southeastern United States. J Med Entomol. 2002; 39(2): 251-255.

40. Paddock CD, Sumner JW, Shore GM, et al. Isolation and characterization of Ehrlichia chaffeensis strains from patients with fatal ehrlichiosis. J Clin Microbiol. 1997; 35(10): 2496-2502. 
41. Clark KL, Savick KM, Butler J. Babesia microti in rodents and raccoons in northeast Florida. J Parasitol. 2012; 98(6): 1117-1121.

42. Hunfeld KP, Hildebrandt A, Gray JS. Babesiosis: recent insights into an ancient disease. Int J Parasitol. 2008; 38(11): 1219-1237.

43. Salina LJ, Greenfield RA, Little SE. Tickborne infections in the southern United States. Am J Med Sci. 2013; 340(3): 194-201.

44. Barbour AG. Isolation and cultivation of Lyme disease spirochetes. Yale J Biol Med. 1984; 57(4): 521-525.

45. Clark K. Borrelia species in host seeking ticks and small mammals in northern Florida. J Clin Microbiol. 2004; 42(11): 5076-5086

46. Johnson B JB, Happ CM, Mayer LW, et al. Detection of Borrelia burgdorferi in ticks by species-specific amplification of the flagellin gene. Am J Trop Med Hyg. 1992; 47(6): 730-741

47. McCombie WR, Heiner C, Kelly JM, et al. Rapid and reliable fluorescent cycle sequencing of double stranded templates. DNA Seq. 1992; 2(5): 289-296.

48. Altschul SF, Gish W, Miller W, et al. Basic local alignment search tool. J Mol Biol. 1990; 215(3): 403-410.

49. Thompson JD, Gibson TJ, Plewniak F, et al. The ClustalX-Windows interface: flexible strategies for multiple sequence alignment aided by quality analysis tools. Nucleic Acids Res. 1997; 25(24): 4876-4882.

50. Saitou N, Nei M. The neighbor-joining method: a new method for reconstructing phylogenetic trees. Mol Biol Evol. 1987; 4(4): 406-425.

51. Swofford DL, Olson GJ, Waddell PJ, et al. Phylogenetic inference. In Molecular Systematics, D. M. Hillis, C. Moritz and B. K. Mable (eds.). Sinauer Associates, Sunderland, MA. 1996; :407-514.

52. Tamura K, Peterson D, Peterson N, et al. MEGA5: Molecular Evolutionary Genetics Analysis using Maximum Likelihood, Evolutionary Distance, and Maximum Parsimony Methods. Mol Biol Evol. 2011; 28(10): 2731-2739.

53. J. Felsenstein. Confidence limits on phylogenies: an approach using the bootstrap. Evolution. 1985; 39:783-791.

54. Tamura K, Nei M, Kumar S. Prospects for inferring very large phylogenies by using the neighbor-joining method. Proc Nat Acad Sci USA. 2004; 101(30): 11030-11035.

55. Rothstein JD, Patel S, Regan MR, et al. Beta-lactam antibiotics offer neuroprotection by increasing glutamate transporter expression. Nature. 2005; 433(7021): 73-77.

56. Castro R, Prieto E, Aguas MJ, et al. Detection of Treponema pallidum sp. pallidum DNA in latent syphilis. Int J STD AIDS. 2007; 18(12): 842-845.

57. Norris DE, Johnson BJ, Piesman J, et al. Culturing selects for specific genotypes of Borrelia burgdorferi in an enzootic cycle in Colorado. J Clin Microbiol. 1997; 35(9): 2359-2364.

58. Fukunaga M, Okada K, Nakao M, et al. Phyologenetic analysis of Borrelia species based on flagellin gene sequences and its application for molecular typing of Lyme disease borreliae. Int J Syst Bacteriol. 1996; 46(4): 898-905.

59. Lebech AM, Hansen K, Wilske B, et al. Taxonomic classification of 29 Borrelia burgdorferi strains isolated from patients with Lyme borreliosis: a comparison of five different phenotypic and genotypic typing schemes. Med Microbiol Immunol. 1994; 183(6): 325-341.

60. Picken RN. Polymerase chain reaction primers and probes derived from flagellin gene sequences for specific detection of the agents of Lyme disease and North American relapsing fever. J Clin Microbiol. 1992; 30(1): 99-114.

61. Yang J, Liu Z, Guan G, et al. Evaluation of molecular methods for detection of Borrelia burgdorferi sensu lato in ticks. Diagn Microbiol Infect Dis. 2012; 73(1): 80-83.

62. Lee SH, Kim BJ, Kim JH, et al. Differentiation of Borrelia burgdorferi sensu lato on the basis of RNA polymerase gene (rpoB) sequences. J Clin Microbiol. 2000; 38(7): 2557-2562.

63. Lee SH, Lee JH, Park HS, et al. Differentiation of Borrelia burgdorferi sensu lato through groEL gene analysis. FEMS Microbiol Lett. 2003; 222(1): 51-57.

64. Lin T, Oliver JH Jr, Gao L, et al. Genetic heterogeneity of Borrelia burgdorferi sensu lato in the southern United States based on restriction fragment length polymorphism and sequence analysis. J Clin Microbiol. 2001; 39(7): 2500-2507.

65. Lin T, Oliver JH Jr, Gao L. Comparative analysis of Borrelia isolates from southeastern USA based on randomly amplified polymorphic DNA fingerprint and $16 \mathrm{~S}$ ribosomal gene sequence analyses. FEMS Microbiol. Lett. 2003; 228(2): 249-257.

66. Wodecka B, Leonska A, Skotarczak B. A comparative analysis of molecular markers for the detection and identification of Borrelia spirochaetes in Ixodes ricinus. J Med Microbiol. 2010; 59(3): 309-314.
67. Stanek G, Reiter M. The expanding Lyme Borrelia complex-clinical significance of genomic species? Clin Microbiol Infect. 2011; 17(4): 487-493.

68. Centers for Disease Control and Prevention. Notice to Readers Recommendations for Test Performance and Interpretation from the Second National Conference on Serologic Diagnosis of Lyme Disease. MMWR. 1995; 44(31): 590-591.

69. Dattwyler RJ, Volkman DJ, Luft BJ, et al. Seronegative Lyme disease. Dissociation of specific T- and B-lymphocyte responses to Borrelia burgdorferi. N Engl J Med. 1988; 319(22): 1441-1446.

70. Schutzer SE, Coyle PK, Belman AL, et al. Sequestration of antibody to Borrelia burgdorferi in immune complexes in seronegative Lyme disease. Lancet. 1990; 335(8685): 312-315.

71. Warshafsky S, Lee DH, Francois LK, et al. Efficacy of antibiotic prophylaxis for the prevention of Lyme disease: an updated systematic review and meta-analysis. J Antimicrob Chemother. 2010; 65(6): 1137-1144.

72. Rogers AJ. A study of the Ixodid ticks of northern Florida, including the biology and life history of Ixodes scapularis Say (Ixodidae: acarina). Doctoral Thesis, University of Maryland. 1953.

73. Mather TN, Mather ME. Intrinsic competence of three ixodid ticks (Acari) as vectors of the Lyme disease spirochete. J Med Entomol. 1990; 27(4): 646-650.

74. Piesman J, Happ CM. Ability of the Lyme disease spirochete Borrelia burgdorferi to infect rodents and three species of human-biting ticks (blacklegged tick, American dog tick, lone star tick) (Acari: Ixodidae). J Med Entomol. 1997; 34(4): 451-456.

75. Sanders FH Jr, Oliver JH Jr. Evaluation of Ixodes scapularis, Amblyomma americanum, and Dermacentor variabilis (Acari: Ixodidae) from Georgia as vectors of a Florida strain of the Lyme disease spirochete, Borrelia burgdorferi. J Med Entomol. 1995; 32(4): 402-406.

76. Norris De, Howell JK, Garza SA, et al. High- and low-infectivity phenotypes of clonal populations of in vitro-cultured Borrelia burgdorferi. Infect Immun. 1995; 63(6): 2206-2212.

77. Feir D, Santanello CR, Li B, et al. Evidence supporting the presence of Borrelia burgdorferi in Missouri. Am J Trop Med Hyg. 1994; 51(4): 475-482.

78. Rosa PA, Hogan D, Schwann TG. Polymerase chain reaction analyses identify two distinct classes of Borrelia burgdorferi. J Clin Microbiol. 1991; 29(3): 524-532.

79. Stromdahl EY, Evans SR, Brien JJ, et al. Prevalence of infection in ticks submitted to the Human Tick Test Kit Program of the U.S. Army Center for Health Promotion and Preventive Medicine. J Med Entomol. 2001; 38(1): 67-74.

80. Scott MC, Harmon JR, Tsao JI, et al. Reverse line blot probe design and polymerase chain reaction optimization for bloodmeal analysis of ticks from the eastern United States. J Med Entomol. 2012; 49(3): 697-709.

81. Hamer SA, Hickling GJ, Keith R, et al. Associations of passerine birds, rabbits, and ticks with Borrelia miyamotoi and Borrelia andersonii in Michigan, U.S.A. Parasit Vectors. 2012; 5: 231. 